\title{
COVID-19 pandemic: Ghana and the geographies of blame
}

\author{
Bernard Owusu (1) - Senanu Kwasi Kutor • Austin Dziwornu Ablo
}

Accepted: 29 December 2021 / Published online: 27 February 2022

(C) The Author(s), under exclusive licence to Springer Nature B.V. 2022

\begin{abstract}
The emergence and the rapid spread of the novel Coronavirus (COVID-19) have resulted in a global public health crisis. The debilitating social and economic impact of the COVID-19 pandemic on vulnerable societies has given rise to questionings, blames, and accusations about how the pandemic has been managed at the national level. This study uses the concept of 'Geographies of blame' to investigate how the national government, citizenry and other stakeholders have blamed each other for the rise in COVID19 cases in Ghana. The study employs a qualitative research approach and administered 45 online surveys to the residents of Accra Metropolis, Ghana, that inquired about who is to be blamed for the rising COVID-19 cases in Ghana. Our results revealed that while the government of Ghana must share the blame due to how they poorly handled the pandemic, the
\end{abstract}

B. Owusu $(\square)$

Department of Geography and Environmental Studies, Wilfrid Laurier University, Waterloo,

ON, Canada

e-mail: owus1530@mylaurier.ca

S. K. Kutor

Department of Geography and Environment, University of Western Ontario, London, ON, Canada

A. D. Ablo

Department of Geography and Resource Development \&

Centre for Humanities, University of Ghana, and

Washington University in St Louis, Legon, Accra/

Missouri, Ghana, USA citizens are more to blame for the spread and continued increase of the COVID-19 cases in the country. Based on the results, the study highlights the need for a pro-active and continuous analysis of the 'babel of blame' as a useful guide to create public awareness and help governments develop and implement strategic plans to tackle the COVID-19 pandemic.

Keywords Geographies of blame - COVID-19 . Pandemic · Citizenry · Government · Ghana

\section{Introduction}

During the last quarter of 2019, rumours of a supposed deadly virus surfaced in China. While the rumours were received with the conviction that the spread of the virus would be limited to its epicentre, unlike H1N1, Ebola, and other epidemics, within three months, the novel Coronavirus (COVID-19) spread worldwide and developed into a global pandemic. A global 'babel of blame' (Sparke \& Anguelow, 2020) emerged. This 'babel of blame' describes how different governments, individuals and other stakeholders attributed the lack of awareness and the spread of the virus in a place and space to different actors across scales (Sparke \& Anguelow, 2020). For example, the 
Table 1 Participants' Demographic information ( Source: Fieldwork (2021))

\begin{tabular}{|c|c|c|c|c|}
\hline Name & Gender & Age Group & Marital status & Educational attainment \\
\hline Grace & Female & $31-40$ & Married & Masters \\
\hline Kofi & Male & $21-30$ & Married & Bachelor \\
\hline John & Male & $21-30$ & Single & Masters \\
\hline Juliet & Female & $21-30$ & Single & Bachelor \\
\hline Frank & Male & $31-40$ & Married & Masters \\
\hline Davies & Male & $21-30$ & Single & Bachelor \\
\hline Felicia & Female & $21-30$ & Married & Masters \\
\hline Charles & Male & $31-40$ & Married & Bachelor \\
\hline Peter & Male & $31-40$ & Married & Bachelor \\
\hline Kpakpo & Male & $31-40$ & Single & Masters \\
\hline $\mathrm{Aku}$ & Female & $21-30$ & Single & Bachelor \\
\hline Atta & Male & $31-40$ & Married & Doctorate \\
\hline Adzo & Female & $21-30$ & Single & Masters \\
\hline Setor & Female & $31-40$ & Single & Bachelor \\
\hline Nancy & Female & $31-40$ & Married & Masters \\
\hline Efua & Female & $41-50$ & Married & Bachelor \\
\hline Gifty & Female & $31-40$ & Single & Masters \\
\hline Naomi & Female & $31-40$ & Single & Masters \\
\hline Bukari & Male & $31-40$ & Single & Masters \\
\hline Alfred & Male & $41-50$ & Married & Bachelor \\
\hline Collins & Male & $31-40$ & Married & Bachelor \\
\hline Alhassan & Male & $31-40$ & Married & Bachelor \\
\hline Samuel & Male & $31-40$ & Married & Bachelor \\
\hline Saviour & Male & $31-40$ & Single & Bachelor \\
\hline Atsu & Male & $31-40$ & Married & Bachelor \\
\hline
\end{tabular}

former USA president-Donald Trump, referred to the virus as the 'China Virus'.

Similarly, migrants and international travellers were blamed for spreading the virus, hence the imposition of travel restrictions and more stringent border controls worldwide. National governments and public health officials, particularly in the US, blamed the WHO for denying the seriousness of the virus and not being suspicious of the Chinese government (Sparke \& Anguelow, 2020). The 'babel of blame' continues to be apportioned to national governments and many countries globally. National governments faced with unprecedented and cascading consequences of the virus on the public continues to institute and implement policies to manage the coronavirus, despite the blame game. In the United States of America, the Donald Trump governments poor management of the pandemic is blamed for the spread of the virus and death toll (Gereffi, 2020). In other contexts, including New Zealand, national leaders have been acclaimed for their effective management of the novel COVID-19 virus (Wilson, 2020).

In Ghana, the COVID-19 pandemic started much more slowly. The first two cases were confirmed in March 2020 when infected foreign nationals from Norway and Turkey arrived (Duncan, 2020). Since then, the number of infected persons has continued rising. The president of Ghana, Nana Akuffo Addo, instituted public health measures and policies which included temporary lockdowns in the Greater Kumasi and Accra metropolitan areas and were strictly enforced by the security services. There was a ban on public gatherings of more than 25 people, and schools were closed (Leah \& Frimpong, 2020; Sibiri et al., 2020).

Similarly, all borders to neighbouring countries were closed and the airport. Also, social distancing 
and public education were promoted to create COVID-19 protocols and awareness among the general public. Just 21 days after the lockdown, the government relaxed with a further directive to ease the restrictions followed in June 2020, at a time when the COVID-19 cases in the country were rising. As of June 2020, the total COVID-19 case increased from 7881 in May 2020 to 17,741 , and the death toll had tripled to 112 (WHO, 2020). Although Ghana has the thirdhighest number of cases in West Africa, the government continued to ease restrictions, ban on social gatherings and other impositions by October 2020.

Like in many places around the world, stakeholders, opposition political party leaders, and individuals blamed the Ghanaian government for its unpreparedness and handling of the pandemic when it emerged. Many health facilities faced a severe shortage of PPEs, intensive care beds and other equipment, which the public and media blamed on the government's inability to procure enough. Many cross-border traders are plying their trade in the sub-region. Those who travel to China and other places also blamed the state for the longer international travel restrictions and border closures. Similarly, blames have been laid at the government's door for limiting and easing the lockdown restrictions after just 21 days in the Greater Accra and Kumasi Metropolitan areas, crucially when there were rising cases. Equally, the government of Ghana has also been blaming the citizenry for disregarding COVID-19 safety protocols. Put differently, the government has been blaming the citizenry for not wearing nose masks, not observing social distancing rules, and not cleaning hands often.

The present pandemic raises fundamental questions about what makes a community, population, and nation sustainable. In a country with a large functioning informal sector such as Ghana, it would have been politically and economically suicidal to have continued to lock down the country for a long time, depriving people of their sources of income and livelihood. The government of Ghana attributed its decision to ease lockdown and border restrictions to improved contact tracing, proper adherence to the COVID-19 guidelines and safety protocols, fumigation exercises and testing.

Studies on the COVID-19 pandemic in Ghana examined the impact of coronavirus on education (see, Adarkwah, 2020; Upoalkpajor \& Upoalkpajor, 2020), its debilitating effects on older adults (see, Gyasi, 2020), its economic costs (see, Amposah \& Frimpong,
2020; Amewu et al., 2020), and public compliance with COVID-19 safety protocols at transportation stations in the Greater Accra region of Ghana (see, Agyemang et al., 2021; Bonful et al., 2020). Similarly, Kutor, et al. (2021) have examined wise reasoning and political leadership in the management of COVID-19. Specifically, they argue that the government's singular act to ease the lockdown restriction amid rising cases is politically induced and did not depict wise reasoning. Despite these foundational and groundbreaking researches, one area that has not received scholarly attention is how the government, stakeholders and the citizenry have apportioned blame to one another in the management, handling and responses to the COVID19 pandemic in Ghana.

We situate this study within the emerging literature of the 'geographies of blame' (Farmer, 2006; Wald, 2008; Roy et al., 2020) within the context of Ghana. Specifically, we interrogate who must be blamed for the spikes in COVID-19 cases and deaths. The paper contributes to the emerging scholarship on COVID-19 with empirical evidence within the context of Ghana. Furthermore, this paper contributes to the literature on the geographies of blame, which has received limited academic attention. The paper demonstrates that while the geographies of blame about rising COVID-19 in Ghana are mixed, the implications for the citizenry and the state are dire if the political leadership does not change its approach in managing COVID-19.

Considering the scale of COVID-19 cases in Ghana, it impacts on the lives of people, and the rate of spread of the virus in recent times means that there is the need to gain insights into how blame is being apportioned notably among stakeholders like the government, healthcare professionals, the media, and citizens. This is critical to understanding the dynamics of the increasing COVID-19 cases in Ghana and policy implications. By deploying geographies of blame as a conceptual lens, this paper adds to the emerging body of scholarly works on the Covid-19 pandemic. Notably, the study shows how the continuous blame game among actors will continue to undermine efforts to curb the spread of the virus. We contend that beyond the transnational scale where countries accuse each other of spreading the virus, at the national level, blame between actors creates suspicion and undermines measures to curb the spread of the virus. This paper is structured as follows. It begins with the theoretical framework of the study. 
The research methods employed are discussed in the next section. The paper then presents the results of the findings. Finally, the article ends with discussions and a conclusion.

\section{Conceptual framing: geographies of blame}

The conceptual framework of 'geographies of blame' inspired the current study. The concept of 'geography of blame' was first used by Paul Farmer (2006) in his book entitled 'AIDS and Accusation: Haiti and the Geography of Blame'. It further inspired other works such as Atlani-Duault et al. (2015) concept of 'Figures of Blame'. Farmer (2006) uses the concept of 'geographies of blame' to describe the spread of HIV/AIDS in the USA. Particularly, Farmer argues that the rise of HIV/AIDS in the USA was attributed to the social relations between North America, precisely the USA and Haiti, which led to the organism responsible for spreading the virus among the human population in the USA. At the same time, the Haitians also blamed the Americans for a series of conspiracy theories. Thus, the spread of diseases is attributed to foreign countries and certain bodies with significant social and economic interdependencies (Wald, 2008; Sparke \& Aguelov, 2020). Atlani-Duault et al. (2015), on conspiracy theories associated with the H1N1 epidemic, explored and developed the concept of 'figures of blame', which further built on Farmer's ideas of 'Geographies of blame'. According to AtlaniDuault et al. (2015), blame is a repetitive action with a long historical root that the advent of social media has not even been able to transform radically. Their study reveals that the constant accusation is often levelled against marginalized groups, immigrants, and societal elites and continues to perpetuate in contemporary times since social media platforms have offered the avenue for it to continue to be expressed. National governments, individuals, key institutions, and stakeholders have become 'figures of blame' (Roy et al., 2020).

Other studies have shown that blame seems to be a recurring feature whenever there are epidemic and pandemic (see, Markel, 2001; Wagner-Egger et al., 2011), conflicts and terrorism and environmental issues worldwide (see Radnitz, 2019; Roy et al., 2020; Smith \& Dressler, 2020). Blames are common as people attempt to scrutinize the actions of others, a situation that could lead to the spread of disease, conflicts and terrorism, and environmental effects of human actions (Farmer, 2006; Radnitz, 2019; Smith \& Dressler, 2020; Tuathail, 2019). For instance, historical patterns of blames and legislation were evident during the USA terrorist attack on 9/11. Smith and Dressler (2020) have also studied colonial historical environmental, geographic forest wildfires and the politics of blames it generates in contemporary times and forest management.

Scholars have sought to address the geographical dimension of pandemics and the geographies of blame implicated in epidemics and global pandemics in various ways. Studies have classified, blamed, and analyzed historical epidemics such as Ebola between 2014 and 2015 in West Africa and the spread of HIV/ AIDS in the USA (see Farmer, 2006; Roy et al., 2020) and the H1N1 in less developing nations (AtlaniDuault et al., 2015). The emphasis and framing of blame in space and place indicate that places are often associated with negative connotations because they are represented geographically and, on the maps, primarily when certain zones and people are classified and considered high-risk groups. Farmer (2006) and Radnitz (2019) demonstrate that Haitians and indigenous people were considered high-risk groups in spreading HIV/AIDS in America and forest wildfires in the colonial Philippines. Their study revealed that people often blame a weak economy and high poverty as crucial factors impacting the spread of pandemics and epidemics (Farmer, 2006; Roy et al., 2020).

Also, by laying 'figures of blame,' people demonstrate their concerns, right and power. As Roy et al. (2020) note, blames lead to a heightened sense of citizenship power to hold national governments and authorities accountable. Other research has highlighted those blames on national governments compelled them to ignore the broader underlying causes of the spread of epidemics such as socioeconomic challenges, including poverty, to focus on what they are accused of not doing. Worth noting is Roy et al.'s (2020) assertion that the outbreak of the Ebola and the spread of the diseases in the affected countries was seen as a border management problem. Hence, it portrayed the government management efforts as inefficient and were made to shirk their responsible and socioeconomic support. However, 'blames' precipitate policy actions (Farmer, 2006; Smith and Dressler, 2020; Radnitz, 2019). National governments impose decrees and legislation with their executive 
powers during and after pandemics, conflicts and terrorism, and environmental blames, further resulting in public scrutiny and actions (Radnitz, 2019; Smith \& Dressler, 2020; Tuathail, 2019).

This study broadly assesses the manifestation of blame and its implication in the advent of the COVID19 pandemic in Ghana. It does not strictly focus on either the positive or negative impacts of the blame. Thus, the paper comprehensively examines the blame game in Ghana, emphasizing the citizenry concerns about the preparedness of the national government and the management of the COVID-19 situation in Ghana and the national government responses and policies to manage the rising COVID-19 cases. Different stakeholders and political figures have blamed and conceptualized the spread of the COVID-19 virus differently. For instance, the former USA president, Donald Trump, called the coronavirus the 'China virus' and always expressed disgust about how the pandemic disrupted human life.

Similarly, Saudi Arabia and South Korea have blamed and lashed out at Irans and Japan for spreading the virus, respectively (Wang, 2020). Likewise, the COVID-19 pandemic has also been attributed to Ramadan related activities accelerating the spread of the virus in the United Kingdom (Sparke \& Aguelov, 2020). The blame-shifting of the spread of the COVID-19 in place and space with its associated economic and social implications continue (Sparke \& Anguelov, 2020), particularly in terms of national governments responses and policies to tackle the spread of the virus and human's vulnerability to the virus. As Roy et al. (2020) assert, blame may foster hope by implying that if a pandemic and an epidemic are humans' creations, they can also find solutions and overcome them. The framework of 'Geography of blame' developed and used by Farmer (2006) provide conceptual guidance to explore who to blame for the rising COVID-19 cases in Ghana. The main advantage of this theoretical framework is that it has direct links with epidemics such as the H1N1 pandemic, ebola and HIV/AIDS. Its analysis includes the blames that culminated in a local context but could be applied to the global context (Pandemic). Also, the analytical component of this framework allows for the nature of blame to be examined in studies.

\section{Methodology}

Study setting and sample population

The study was conducted in the Accra Metropolis of Ghana. The Accra Metropolis is one of Ghana's 216 Metropolitan, Municipal and District Assemblies (MMDAs). It is also among the 16 MMDAs in the Greater Accra Region of Ghana. The Accra Metropolis was established by the Local Government Act, 1993 (Act 462) and Legislative Instrument 1615. However, due to metamorphoses in size and number of sub-metros, the current Accra Metropolis was established in 2012 with Legislative Instrument 2034 following the creation of the La Dadekotopon Municipal Area. According to the 2010 population and Housing census, the Accra Metropolis/AMA has a population of $1,665,086$ (48.1\% and $51.9 \%$ representing males and females, respectively (GSS, 2014). The study area is entirely urban. The statistics also revealed that of the population 11 years and above, $89 \%$ are literate and $11 \%$ are illiterate-with five out of ten people (52.\%) indicating that they could speak and write both English and Ghanaian languages (GSS, 2014). The high literacy level of the study context made it plausible to rely on an online qualitative survey to investigate this critical research question. Additionally, it was revealed that the population 12 years and above (75.4\%) used mobile phones where men and women ownership of mobile phones was rated at $49.9 \%$ and $50.1 \%$, respectively.

A total of 45 questionnaires were sent by email and WhatsApp, but only 25 participants responded comprehensively, comprising 15 males and ten females. Fourteen participants hold a bachelor's degree, ten have a master's degree, and one holds a doctorate. This is unsurprising considering the medium used in administering the questionnaire, which requires proficiency in the English language. Demographically, seven participants were between 21 and 30 years of age, two between 41 and 50, and 16 between 31 and 40 years of age. Out of the 25 people who responded to the survey, 14 were married, while the remaining 11 were not married. We used pseudonyms in place of participants names to ensure anonymity. As Baxter and Eyles (1997) noted, some ways of guaranteeing rigour and credibility in qualitative research are providing information on the appropriateness of 
methodology and the presentation of verbatim quotations.

Research design, data collection and analysis

The study utilized an exploratory qualitative design to examine the 'geographies of blame' among residents of the Accra Metropolitan Area or Accra Metropolis, Ghana. An exploratory qualitative research design was used due to the paucity of research on COVID-19 and the blame game. Worth noting is Stevens and Wrenn (2012) argument that exploratory research is needed to generate ideas, provide insights, and increase researchers understanding of an issue. Thus, the exploratory qualitative approach was vital to create new insights into how pandemics, such as COVID-19, was fraught with blame game between relevant stakeholders, including the citizenry. Due to the context and implications of the pandemic, the nonprobability sampling method was used. Specifically, convenience sampling was used because of easy accessibility to participants, their availability, and willingness to participate in the study. After generating the google forms, the link is shared through authors' social networks who were encouraged to share the links among their ties to adults resident in Accra.

We employed an open-ended online qualitative survey to understand from the lived experiences of the residents of Accra Metropolis concerning who was to be blamed for the current spikes in COVID-19 cases. Specifically, an online qualitative survey was used because it was not practical to conduct one-on-one indepth interviews in a pandemic period. An online qualitative study "consists of a series of standardized questions presented to a participant to provide textual data without further interaction with an interviewer or researcher" (Neville et al., 2016: 660). Due to the novelty of COVID-19, our preference for the online qualitative survey was coherent with Braun et al. (2021: 1) assertion that "primary method, qualitative surveys seek to harness the potential qualitative data offer for nuanced, in-depth and sometimes new understandings of social issues." A qualitative online survey captured participants' subjective understandings, practices, discourses, and accounts like conventional in-depth interviews. This produced rich and multi-layered interpretations of their sense-making because participants respond by typing answers in their own words rather than selecting from predetermined choices (Braun \& Clarke, 2013).

Google Forms was used to collect data for the study. Google Forms is a cloud-based management instrument used for designing and developing webbased surveys. The use of Google Forms was consistent with Mansor's (2012) assertion that google forms are beneficial for gathering responses to open-ended questions and conducting online quizzes. An automatic Web URL for the survey in Google Forms was generated. The URL link was then forwarded through online platforms. Because we used WhatsApp and standard emails to reach our target participants, we expected people with internet access and who can read and write English to respond to the survey. Once the participants answered the survey, the data was instinctively recorded in a Google spreadsheet. The detailed written responses were analyzed using open coding techniques (Crang 2005), involving assigning recurrent themes besides written texts and sentences as they emerged. The dominant reasons why the government, individuals or other relevant stakeholders should be blamed were used as the criteria for building and grouping themes and subthemes. The study aimed to generate information on the relationship between geographies of blame and the COVID-19 pandemic in Ghana. There has not been any previous research on geographies of blame and COVID-19. We also drew on and integrated the grey literature and media articles into the online data to give a robust overview of the 'babel of blame' that characterized Ghana's COVID19 management, especially after the general elections held in December 2020.

\section{Results and discussion}

Geographies of blame 1: individuals culpability?

From the online qualitative survey, there is abundant evidence that demonstrates that predominantly, individuals are to be blamed for the current rising COVID19 cases and death in Ghana. A recurrent theme emphasizing the culpability of individuals is their reluctance to strictly follow COVID-19 protocols of wearing nose masks and keeping social distancing, all aimed at preventing the diffusion of COVID-19. Some participants believe that the government has carried out enough public, and the public must follow the 
guidelines to at least slow the spread of the virus. A young woman is among several participants who shared this sentiment. According to her:

The government cannot be blamed because it has played its role in curtailing the initial spread [of the virus]. It is up to individuals and organizations to adhere to the protocols to minimize the spread of the disease (Grace, Female participant).

Grace's view above is supported by other participants who noted that:

The government cannot be blamed since all COVID -19 protocols have been issued-its implementation being [keeping social] distance, at least 6feet, mask-wearing, hands sanitizing, and staying home than roaming in town and public spaces. When affected, just visit the nearest health facility to report for a further recommendation on getting treatment since designated facilities are not spatially represented (Kofi, Male participant).

[The] government has done its best by sensitizing the people of Ghana and has given citizens the safety rules to follow to stay safe. Therefore, it is up to us, the individuals, to respect and obey authorities to curtail the spread of the virus. Without that, there is absolutely nothing the government can do. (John, Male participant).

Participants noted that the government could not police over 30 million Ghanaians daily to ensure that they comply with the wearing of nose masks or to ensure citizenry religiously follow other safety protocols. The view is that citizens have a responsibility to adhere to the safety protocols instituted by the government. People's refusal to observe safety guidelines should therefore not be blamed on the government. Overarchingly, had individuals followed the safety guidelines and protocols, the country would not be experiencing the current alarming COVID-19 cases and deaths. The need for an attitudinal shift is echoed in one of the participants' narrations in combating the pandemic. According to her, the "attitude of the people is paramount in the fight against this pandemic. And they refused to abide by the protocol put in place to stop this pandemic" (Juliet, Female participant). This sentiment is equally expressed by other participants, including Frank and Davies. Their assertions are reflected in the quotations below:

The individuals have to be held responsible or blamed for the current surge in Covid-19 cases. This is because the government has done its part by educating the people and providing support. The onus now lies on the individuals to help fight the pandemic. But what do we see? Individuals act recklessly, contributing to the worsening situation we find ourselves in now (Frank, Male participant).

Although implementation is virtually nonexistent, individuals have a [critical] role in protecting themselves and thereby protecting others. Following laid down protocols is the sole responsibility of the individual. The government can only enforce the safety protocol to some extent. The chunk of the responsibility is on the individual, so I think individuals have to be blamed for the current rising COVID-19 cases in our country (Davies, Male participant).

The above narratives demonstrated that the current COVID-19 situation is a concern to the participants. The participants' perspectives illustrated above show that individuals, to a large extent, are to be blamed for the disturbing rising cases. The unwillingness of individuals to follow the COVID-19 safety protocols and individuals' reckless behaviours are undermining government efforts to combat the pandemic. Even though the rising COVID-19 cases have dire repercussions for the reckless individuals, it equally has wider implications for others, including the health architecture in Ghana and the impacts on the national economy if cases are out of control. Several participants equally echoed this sentiment, including a female participant who narrated: "the fact that health facilities are running out of space, health workers are exhausted, lives are being lost every day, these pose a dangerous challenge to the country both at the short and long term. This should make anybody at all concerned" (Felicia, Female participant).

Geographies of blame 2: government at fault?

The lacklustre management approach by the government also accounted for the increased case counts in Ghana. One of the recurrent themes why the 
participants blamed the government was the lack of trust and confidence in the political leadership. The lack of trust in political leadership is contingent on how political leadership and its actors' actions are not in tandem with their policy narratives concerning COVID-19. For instance, while the political leaders, on the one hand, keep urging the population to observe safety protocols, they engaged in political campaigns and health walks, all aimed at mobilizing voters in the 2020 election. Therefore, it was not surprising that immediately after the political campaign and election seasons, COVID-19 cases were skyrocketing. A male participant expressed this feeling. According to him, "political rallies and campaigns were conducted amidst the COVID-19. Therefore, the government should be blamed for the current situation" (Charles, Male participant).

Similarly, several participants corroborated Charles' sentiment, including a female participant and another male participant. Their narratives are reflected in the quotations below:

The government should be blamed for this. [The] government was too irresponsible during the campaign and electioneering period. They didn't observe most of the protocols to curb the spread. You will see large crowds following these political actors and, most importantly, no respect for nose masks and social distancing. The fee for testing, too, is too high. (Felicia, Female participant).

The inaction of the government to control the first 2 cases led us to where we are now and also [making] the general populace in believing the virus had gone down during the election time that led many people to disregard the safety protocols that brought us to this point (Peter, Male participant).

The lack of enforcement of safety protocols and guidelines is another recurrent theme from the study to epitomize why the government must also be blamed for the rising cases. This manifests in the government's inability to enforce its own rules on adherence to enhanced hygiene, social distancing and maskwearing protocols, and the ban on public gatherings. The government, on several occasions, kept echoing those prohibitions on public gatherings and the closure of restaurants, bars, and nightclubs are in effect.
However, the media landscape is engulfed with stories, cases, videos, and images of people partying and patronizing the 'so called' spaces that are deemed closed by the government directives. When asked about who is to be blamed for the alarming increment in COVID-19 cases, a male participant stated that "inadequate commitment towards the implementation of safety protocols by monitoring to ensure the right things are being done and the populace adhering to the protocols" (Kpakpo, Male participant). Inherent in Kpakpo's narration demonstrates that the government of Ghana is not committed to strict enforcement of their safety protocols, which defiance attract a set of sanctions.

Relatedly, Kpakpo is not alone in this dilemma. Respondents like Akua and Atta share similar sentiments:

[While]the individuals should be partly blamed for this, the government should hold a larger portion of the blame in that individuals/citizens succumb to the government's orders of the day. The government holds all authority and power to make and enforce strict rules that protect its people. The government failed to put strict rules in place, thereby leaving everyone to their fate. (Aku, Female participant).

Since there has been the imposition of various restrictions and protocols to control and manage the infection rate, implementation by the state agencies whose responsibility it is, is nonexistent. Instituting policies without implementation is as useless as not having policies (Atta, Male participant).

The above narratives underscore how cross-sections of the residents of Accra Metropolis feel about who must be blamed for the surge in COVID-19 cases in Ghana. The participants indicated they are concerned about the increasing cases. As one of the participants emphasized why he is concerned, he narrated: "the virus as it stands now is affecting societies and the venerable across Ghana. It has caused fear and panic in many, for that matter affecting businesses' social programs. Families of those who lost their lives through this pandemic have suffered pain. These happenings make me concerned about the increasing cases" (Davies, Male participant). Aside from individuals, the participants also blamed the government 
for showing a lack of enforcement of the safety protocols. It is worth mentioning that countries that are doing well in keeping the virus under control are implementing and enforcing the safety protocols. However, in Ghana, the government is not effectively committed to fighting the pandemic. The government's inability to control the virus is evident in the political leadership's action, which is at variance with their policy narratives regarding COVID-19 management.

\section{Discussion}

Since the outbreak of the novel COVID-19, national governments and health institutions across the world have been the critical agencies at the forefront of finding solutions to combat the spread of the virus. The situation is the same in Ghana. The national governments play a crucial role in making decisions on the management of the COVID-19 cases and ensuring the availability of resources needed for the effective administration of the COVID-19. The health facilities under the Ministry of Health in Ghana, with the support of the World Health Organization, undertake antigen testing and put an emergency preparedness and response plan to guide, prevent, control, and manage the COVID-19 infection in Ghana. Despite their crucial roles, COVID-19 cases are rising, with Ghana moving from third to the seventh position with the COVID-19 cases behind South Africa, Ethiopia, Kenya, Nigeria, Zambia and Algeria within the African continent (Agbozo \& Jahn, 2021).

This study uses Farmer (2006) 's Geography of blame as the main conceptual framework to explore and ascertain who to be blamed for the surge in COVID-19 cases in Ghana from the residents of Accra Metropolis, Ghana. The application of the geographies of blame to the COVID-19 situation in Ghana is novel and the first of its kind compared to other studies that have examined the socioeconomic impacts on people. For example, while Agbozo and Jahn (2021) have examined the effects of COVID-19 on maternal health, on the one hand, Yendork and James (2020), on the other hand, have interrogated the impact of COVID-19 on government policies and diverse sectors in Ghana as a whole. It must be emphasized that the novel COVID-19 pandemic has brought many global changes. The economic, political, and social impacts are enormous in Ghana (Yendork \& James, 2020; Agbozo and James 2021), leading to scrutiny over citizenry's adherence to the COVID-19 guidelines, protocols, and national governments response to the spread of the virus. Thus, the continued scrutiny and accusations are invariably linked to the understanding and applying the concept of 'geographies of blame' in the local context, which this paper explores through an online qualitative survey.

The current study's findings are mixed, as participants blamed both the citizenry and the government of Ghana for the increasing COVID-19 cases in the country. Specifically, some participants blamed the government of Ghana for the rising COVID-19 cases in the country. The participants stressed that the government of Ghana was not very firm in its policy implementation when it was needed the most. This assertion by the participants is manifested in the government's attitude towards handling the pandemic in the country, precisely the lifting of bans with very little attention paid to the daily recorded cases, unlike when the pandemic first began. Further, the participant emphasized in their responses that the government used the period as an opportunity for electioneering campaigns and electoral processes; hence the government must answer for the spike in COVID-19 cases.

Similarly, participants blamed the national government and its agencies for the poor implementation and enforcement of the COVID-19 protocols and guidelines. This assertion is consistent with the earlier work of scholars, including Roy et al. (2020), on the Ebola epidemic, where people blamed the national governments of some West African countries on social media platforms, including Twitter, for their poor handling of the Ebola diseases. However, our specific finding contradicts the findings of other studies where the blame is directed at institutions, both political and health authorities, during pandemics (see, Major et al., 2013; Joffie, 2011). For instance, with the 2009/10 Swine Flu pandemic, the blame of the swine flu was directed at political and health institutions (Joffie, 2011), unlike in our study where the blame is primarily directed at the government and the citizenry.

Thus, the blame game has a dual effect of preventing action on the one hand and leading to positive action on the other. Based on media narratives concerning the government of Ghana's responses to the accusation of being responsible for the rising cases of COVID-19, it does suggest that the blame game 
does not culminate in the shirking of responsibilities by the government and relevant stakeholders, especially the Ministry of Health and Ghana Health Service. Specifically, a careful evaluation of the government and public health officials' actions, directives, and speeches demonstrate their concerted efforts to manage the pandemic through the fivestaged policy programs effectively: limit and stop the importation of virus; prevent community spread; isolate, treat, and take care of the sick; ensure selfreliance and expand domestic ability; and limit the effect on social and economic life (see Sibiri et al., 2020) despite the claims of being responsible for rising cases.

Further, this study shows that the Ghanaian public is to be blamed for the surge in the COVID-19 cases in the country. The participants alluded to the increasingly COVID-19 cases to ignorance, reckless lifestyle, and non-adherence to the COVID-19 safety protocols. Ghana has a substantial informal sector; therefore, prolonged lockdowns and restrictions will impact people's income, livelihoods and survival of the citizenry involved in the sector. Consequently, the citizenry's commuting patterns between their homes, workplaces, and economic activities to sustain their livelihood exposes them and others to the coronavirus since they do not adhere to safety protocols. Also, the citizen's mobility encompasses the movement from high COVID-19 risk geographical areas to less risky zones, leading to a situation where there is a higher tendency to spread the virus. This situation is consistent with the concept of geography of blame as demonstrated in Farmer's (2006) work on HIV/AIDS scrutiny and accusations. According to Farmer (2006), economic interdependences between nations led to HIV/AIDS in America. He showed in his work that Haitian migrants who had moved to America for economic gains were blamed for spreading HIV in the country on the assumption of the rampant nature of HIV in Haiti.

Similarly, likely, the movement of the Ghanaian citizenry from the epicentre and hotspots of the virus in the country for trade, retailing, and other forms of buying and selling might increase the chances of exposure to the COVID-19 cases hence the recent rise in the number of daily cases recorded. Relatedly, a recent article demonstrated how it is easy for national governments to hide behind reckless lifestyles, poor choices, and adherence of the citizenry to COVID-19 protocols (Owen), thereby directing the blame to the doorstep of the citizenry. The author emphasized that shifting the blame to the citizens for the rise in COVID-19 cases let the British government off the hook. Thus, while the citizenry scrutinized and accused the government, on the one hand, the government, on the other hand, equally blamed the citizenry for the surging COVID-19 cases. These findings and conclusions suggest that both citizens and the government have blamed each other regarding the COVID-19 pandemic situation.

\section{Limitations of the study}

Notwithstanding the new insights gleaned from the study, some limitations of this study must be recognized. First, the study is an exploratory study and, therefore, not meant for generalization. Rather, it seeks to explore geographies of blame and COVID-19 and thereby generate information for further studies. Second, our findings are skewed towards the participants who participated in the study. Because the study employed an online data collection technique, it automatically excluded those who were not literate and technologically savvy. Future research on the geographies of blame and the COVID-19 pandemic should also target participants in the informal sector of the Ghanaian economy. Third, the current study is silent on what other stakeholders, especially the Ghana government, think about the blame game question regarding COVID-19 rising cases. Therefore, future research should interrogate these issues from multiple viewpoints, especially from the government of Ghana.

\section{Conclusion}

In an era of the global pandemic, there are increasing accusations and blame game among stakeholders, citizenry, national governments and non-government organizations. The blame centred on the emergence of the virus, responses, policy implementation to curtail the pandemic, and the current surge in COVID-19 cases in both the developed and developing economies. This blame game resonates well with the concept of 'geographies of blame' among geographers. Our target population-a cross-section of the residents of Accra Metropolis indicated mixed responses regarding who to be blamed for the surge 
in COVID-19 cases in Ghana. Put differently, our research findings are mixed regarding who should be blamed for the current COVID-19 situation in Ghana. Essentially, the results revealed that individuals are to be blamed for rising Covid-19 cases. However, a section of the participants also indicated that the government of Ghana could not be ignored; hence they must share the blame. Many cited the government's decision to ease restrictions for electioneering campaigns and non-enforcement of safety protocols as some of the reasons for her culpability. The citizen's reckless behaviour and actions of not adhering to COVID-19 guidelines and protocols, especially wearing nose masks, social and physical distancing, and frequent hand washing, are apparent reasons for the citizenry's culpability regarding the geographies of blame regarding COVID-19.

In general, this study demonstrates that the rising cases of the COVID-19 pandemic present an opportunity to apply the concept of the 'Geographies of Blame' and further put it into local context-in this case, the blame game concerning the increasing COVID-19 cases in Ghana. The study adds to the emerging literature on the COVID-19 pandemic. It extends the scholarship on the geographies of blame that have also examined various epidemics such as HIV/AIDS and Ebola. The study serves as a good foundation for further studies to examine appropriate policy and interventions to manage and curtail the rising COVID-19 cases in Ghana. Thus, the ongoing 'babel of blame' is a valuable guide to create awareness, put stakeholders on their toes and help the government develop and implement strategic plans in combating pandemics, including COVID-19. Equally, the conceptual framework of geographies of the blame can be deployed in other disciplines to interrogate issues fraught with blame games. Such endeavour would culminate in what Kutor, Amoak, et al. (2021) described as creating an avenue for dialogue among diverse disciplines. However, beyond the blame dynamics, awareness and concern shown by individuals on the COVID-19 can help Ghanaian health authorities and the government to clearly understand the public attitude to the threat of the COVID-19 pandemic. Together, all the stakeholders could then hope for strategies and health interventions to be targeted, instituted and implemented accordingly to counter attempted blames and improve management of the COVID-19 crisis and other future eventualities.

Funding The author(s) received no financial support for the research, authorship, and publication of this article.

\section{Declarations}

Conflict of interests There are no potential conflicts of interest concerning this article's research, authorship, and publication.

\section{References}

Adarkwah, M. A. (2020). I'm not against online teaching, but what about us?: ICT in Ghana post Covid-19. Education and Information Technologies, 26(2), 1-21.

Agbozo and Jahn. (2021). COVID-19 in Ghana: Challenges and the counter measures for mental health service delivery in public health facilities. Reproductive Health, 18(1), 151.

Agyemang E, Agyei-Mensah S, Kyere-Gyeabour E. Face mask use among commercial drivers during the COVID-19 pandemic in Accra, Ghana. Journal of Community Health, 46(6), 1226-1235. https://doi.org/10.1007/s10900-02101004-0.

Amewu, S., Asante, S., Pauw, K., \& Thurlow, J. (2020). The economic costs of COVID-19 in sub-Saharan Africa: Insights from a simulation exercise for Ghana. The European Journal of Development Research, 32(5), 1353-1378.

Amponsah, R., \& Frimpong, I. A. (2020). Ghana in the Face of COVID-19: Economic impact of coronavirus (2019NCOV) outbreak on Ghana. Open Journal of Business and Management, 8(04), 1404.

Atlani-Duault, L., Mercier, A., Rousseau, C., Guyot, P., \& Moatti, J. P. (2015). Blood libel rebooted: Traditional scapegoats, online media, and the H1N1 epidemic. Culture, Medicine, and Psychiatry, 39, 43-61.

Baxter, J., \& Eyles, J. (1997). Evaluating qualitative research in social geography: Establishing "rigour" in interview analysis. Transactions of the Institute of British Geographers, 22(4), 505-525.

Bonful, H. A., Addo-Lartey, A., Aheto, J. M., Ganle, J. K., Sarfo, B., \& Aryeetey, R. (2020). Limiting spread of COVID-19 in Ghana: Compliance audit of selected transportation stations in the Greater Accra region of Ghana. PLoS ONE, 15(9), e0238971.

Braun, V., \& Clarke, V. (2013). Successful qualitative research: A practical guide for beginners. London: Sage.

Braun, V., Clarke, V., Boulton, E., Davey, L., \& McEvoy, C. (2021). The online survey as a qualitative research tool.International Journal of Social Research Methodology, 24(6), 641-654.

Crang, P. (2005). Analyzing qualitative materials. In R. Flowerdew, \& D. Martin. (Eds.), Methods in humangeography: A guide for students doing a research project (2nd Ed., pp. 218-232). Essex: Pearson Educational.

Duncan, J. (2020). Two cases of the coronavirus confirmed in Ghana. Citi Newsroom. Retrieved March 16, 2020 from 
https://citinewsroom.com/2020/03/two-cases-ofcoronavirus-confirmed-in-ghana/

Farmer, P. (2006). AIDS and accusation: Haiti and the Geography of blame. University of California Press.

Gereffi, G. (2020). What does the COVID-19 pandemic teach us about global value chains? The case of medical supplies. Journal of International Business Policy, 3(3), 287-301. https://doi.org/10.1057/s42214-020-00062-w

Ghana Statistical Service (GSS). (2014). 2010 Population and housing census. District analytical report, Accra Metropolitan. Accra: Ghana Statistical Service. Retrieved from https://www2.statsghana.gov.gh/docfiles/2010_ District_Report/Greater\%20Accra/AMA.pdf.

Gyasi, R. M. (2020). Fighting COVID-19: Fear and internal conflict among older adults in Ghana. Journal of Gerontological Social Work, 63(6-7), 688-690.

Joffe, H. (2011). Public apprehension of emerging infectious diseases: Are changes afoot? Public Understanding of Science, 20(4), 446-460.

Kutor, S. K., Amoak, D., Owusu, B., \& Kyeremeh, E. (2021). Theorising' wicked concept' and reconceptualising wisdom as wicked. The Professional Geographer, 73(4), 932. https://doi.org/10.1080/00330124.2021.1933553

Kutor, S. K., Kyeremeh, E., Owusu, B., Amoak, D., \& Ishola, T. O. (2021). Wise reasoning and political leadership amid COVID-19 pandemic in Ghana. International Journal of Public Leadership, 28(1), 4. https://doi.org/10.1108/IJPL03-2021-0018

Leah, H. M., \& Frimpong, F. B. (2020). The pandemic and the economy of Africa: Conflicting strategies between Tanzania and Ghana. Digital Government: Research and Practice, 1(4). https://doi.org/10.1145/3419217

Mansor, A. Z. (2012). Managing students' grades and attendance records using google forms and google spreadsheets. Procedia-Social and Behavioral Sciences, 59, 420-428.

Markel, H. (2001). Journals of the plague years: Documenting the history of the AIDS epidemic in the United States. American Journal of Public Health, 91(7), 1025-1028.

Mayor, E., Eicher, V., Bangerter, A., Gilles, I., Clémence, A., \& Green, E. G. (2013). Dynamic social representations of the 2009 H1N1 pandemic: Shifting patterns of sense-making and blame. Public Understanding of Science, 22(8), 1011-1024.

Neville, S., Adams, J., \& Cook, C. (2016). Using internet-based approaches to collect qualitative data from vulnerable groups: Reflections from the field. Contemporary Nurse, 52(6), 657-668.

Owen, J. (2020). Blaming the public for a rise in the COVID Lets the government off the Hook. The guardian.Retrieved June 11,2021 from https://www.theguardian.com/ commentisfree/2020/dec/23/blaming-public-rise-covidpress-ministers.

Radnitz, S. (2019). Reinterpreting the enemy: Geopolitical beliefs and the attribution of blame in the nagorno-karabakh conflict. Political Geography, 70(2019), 64-73.
Roy, M., Moreau, N., Rousseau, C., Mercier., A, Wilson, \& Atlani-Duault., L. (2020). Ebola and localized blame on social media: Analysis of Twitter and Facebook conversations during the 2014-2015 Ebola epidemic. Culture, Medicine and Psychiatry, 44(1), 56-79. https://doi.org/10. 1007/s11013-019-09635-8.

Sibiri, H., Prah, D., \& Zankawah, S. M. (2020). Containing the impact of COVID-19: Review of Ghana's response approach. Health Policy and Technology, 10(1), 13-15.

Smith, W., \& Dressler, W. H. (2020). Forged in flames: Indigeneity, forest fire and geographies of blame in the Philippines. Postcolonial Studies, 23(4), 527-545. https:// doi.org/10.1080/13688790.2020.1745620.

Sparke, M. \& Anguelov, D. (2020). Contextualizing coronavirus geographically. Transactions of the Institute of British Geographers. https://doi.org/10.1111/tran.12389.

Stevens, L., \& Wrenn, C. (2012). Exploratory (qualitative) research. In R. Stevens, D. Loudon, B. Wrenn, \& H. Cole (Eds.), Concise encyclopedia of church and religious organization marketing (pp. 53-56). New York: Routledge.

Tuathail, G. O. (2019). Placing blame: Making sense of beslan. Political Geography, 28(1), 4-15.

Upoalkpajor, J. L. N, \& Upoalkpajor, C. B. (2020). The impact of COVID-19 on education in Ghana. Asian Journal of Education and Social studies, 9(1), 23-33.

Wagner-Egger, P., Bangerter, A., Gilles, I., Green, E., Rigaud, D., Krings, F., Staerkle', C., \& Cle'mence, A. (2011). Lay perceptions of collectives at the outbreak of the H1N1 epidemic: Heroes, villains and victims. Public Understanding of Science, 20(4), 461-476.

Wald, P. (2008). Contagious: Cultures carriers and the outbreak narrative. Durham: Duke University Press.

Wang V, (2020) As death toll mounts, Governments point fingers over coronavirus https://www.nytimes.com/2020/03/ 06/world/coronavirus-world.html?auth=link-dismissgoogle1tap

WHO. (2020). Coronavirus disease (COVID-19) situation report 163 (PDF). World Health Organization. Retrieved September 20, 202 from https://reliefweb.int/report/world/ coronavirus-disease-covid-19-situation-report-163-1-july2020

Wilson S (2020). Three reasons why Jacinda Ardern's coronavirus response has been a masterclass in crisis leadership. The Conversation. https://theconversation.com/threereasons-why-jacinda-arderns-coronavirus-response-hasbeen-a-masterclass-in-crisis-leadership-135541 (April 05, 2020).

Yendork, S. J., \& James, S. (2020). COVID-19 in Ghana: Changes and the way forward. Journal of Comparative Studies, 51(3-4), 369-384.

Publisher's Note Springer Nature remains neutral with regard to jurisdictional claims in published maps and institutional affiliations. 